\title{
Movimiento pendular: proyectos de educación patrimonial entre la esfera formal y la informal. El Programa Pintia de Innovación Educativa y la Fiesta del Vino de Viver
}

\author{
Pendulum movement: heritage education projects between the formal and informal \\ spheres. The Pintia Program of Educational Innovation and \\ The Wine Festival of Viver
}

\author{
Pablo De Castro, ${ }^{a}$ Angel Portolés ${ }^{b}$ \\ aDepartamento de didáctica de la expresión musical, plástica y corporal, Universidad de Valladolid \\ Correo electrónico: tartesos.pablo@gmail.com

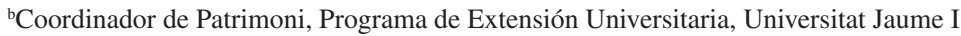 \\ Correo electrónico: aportole@uji.es
}

\begin{abstract}
RESUMEN
La educación patrimonial es un viaje con enfoques diversos en el que el propio patrimonio, ya sea material o inmaterial, puede considerarse el origen, convertirse en un fin o transformarse en el medio del proceso educativo. En este contexto, los ámbitos de la educación formal e informal suelen presentarse como independientes, a lo sumo como complementarios, pero rara vez fluyen, conectados entre sí, en un mismo proyecto educativo. El presente artículo traza un itinerario pendular presentando dos proyectos de educación patrimonial - La fiesta del vino de Viver y el Programa Pintia de Innovación Educativa-, donde la proyección y la continuidad desmontan esta tradicional dialéctica entre estos ámbitos educativos. La enseñanza del patrimonio histórico, desde los procesos de identización y construcción de sentimientos de pertenencia, y la implementación de un diseño participativo y horizontal, cargado de creatividad, constituyen los ejes principales de un diálogo en el que también se identifican el trabajo colaborativo o la mirada sobre la memoria y el territorio.
\end{abstract}

Palabras clave: educación patrimonial, identización, socialización, participación.

\section{SUMMARY}

Heritage education is a journey with diverse approaches in which one's own heritage, whether material or immaterial, can be considered the origin, become an end or become the middle of the educational process. In this context, the fields of formal and informal education are often presented as independent, at best complementary, but they rarely flow, connected to each other, in the same educational project. This paper traces its itinerary presenting two patrimonial education projects - Viver Wine Festival and the Pintia Program of Educational Innovation -, where projection and ongoing processes dismantle this traditional dialectic between these educational fields. The teaching of historical heritage, from the processes of identization and construction of senses of belonging, and the implementation of a participatory and horizontal design, full of creativity, are the main axes of a dialogue in which also identify the collaborative work or the Look at memory and territory.

Keywords: heritage education, identization, socialization, participation. 
MOVIMIENTO PENDULAR: PROYECTOS DE EDUCACIÓN PATRIMONIAL ENTRE LA ESFERA FORMAL Y LA INFORMAL. EL PROGRAMA PINTIA DE INNOVACIÓN EDUCATIVA Y LA FIESTA DEL VINO DE VIVER

\section{EL HILO DEL PÉNDULO}

El contenido de la expresión "patrimonio cultural" ha cambiado bastante en las últimas décadas, debido en parte a los instrumentos elaborados por la UNESCO. El patrimonio cultural no se limita a monumentos y colecciones de objetos, sino que comprende también tradiciones o expresiones vivas heredadas de nuestros antepasados y transmitidas a nuestros descendientes, como tradiciones orales, artes del espectáculo, usos sociales, rituales, actos festivos, conocimientos y prácticas relativos a la naturaleza y el universo, y saberes y técnicas vinculados a la artesanía tradicional. (UNESCO, 2003).

Nos parecía oportuno comenzar el artículo con esta cita extraída de la página web de UNESCO, en la que se percibe la evolución natural del concepto de patrimonio, ampliándose con el llamado patrimonio inmaterial, de modo análogo a cómo la práctica pedagógica y el acompañamiento que se presentan a través de los dos proyectos de educación patrimonial que se describen en este texto, el Programa Pintia de Innovación Educativa y el proyecto de la Fiesta del Vino de Viver, son la consecuencia de una manera evolucionada de comprender la cultura, la arqueología, el patrimonio, la Historia del Arte o la tradición ${ }^{1}$.

El manejo combinado de las posibles perspectivas de estudio existentes para el acercamiento al patrimonio -histórica, sociológica, formal e iconológica-, esta acentuación de una suerte de multifocalidad a la hora de desarrollar el Programa Pintia o la Fiesta del Vino de Viver, nos ha permitido trabajar en los proyectos liberándonos de los corsés educativos más tradicionales y alejarnos de la imitación inconsciente y/o acomodaticia de rancios patrones que, por años de repetición, aún hoy imperan en los ámbitos de la enseñanza formal e informal.

Nuestros trabajos en torno a los contenidos de educación artística y patrimonial se encuentran en la línea propuesta por Calaf y Fontal cuando desglosan su planteamiento para reformar la enseñanza del arte en el siglo XXI (Calaf \& Fontal, 2010), una línea de acción que utiliza aquellos criterios metodológicos y estrategias de enseñanza-aprendizaje que hagan posible la construcción de aprendizajes nuevos y más eficaces (Calaf \& Fontal, 2010).

Así, no es extraño encontrar en las propuestas que vamos a presentar a continuación o, en general, en el aprendizaje basado en proyectos -que, en cierto modo, es el trasfondo metodológico que funciona como hilo del péndulo en este viaje de vaivén entre Pintia y Viver, así como, también, entre la educación formal y la no formal-, planteamientos que se desmarcan de estrategias consideradas más o menos convencionales, como el empleo de perspectivas de análisis no lineales, nuevas estrategias para la ordenación de la Historia del Arte o el Patrimonio, argumentaciones desde relatos construidos sobre piezas emblemáticas, el diálogo multidireccional creador obra observador, la consideración de la obra como "obra abierta" (Eco, 1984, p. 12) o la mirada subjetiva.

En nuestros proyectos existe una apuesta consciente por educar en los procedimientos y actitudes que permitan comprender el patrimonio dentro de un contexto o contextos

Juanola y Calbó (2004) recogen la confusión que, según Maurizzio Vitta (2003), ha perdurado hasta hoy con relación a la Historia del Arte, al ser entendida como una historia de la belleza, separándola de lo cotidiano para vincularla, únicamente, con lo excepcional. 
concretos, ya sea partiendo del propio bien patrimonial -percepciones multisensoriales, compartidas, selectivas, por capas o cotidianas-o comenzando en las actitudes del espectador frente al hecho artístico -o el bien patrimonial- y singularizar estos aprendizajes con un entorno adecuado y numerosas experiencias educativas extramuros de las instituciones educativas (Juanola \& Calbó, 2004).

En los proyectos sobre el mundo vacceo o sobre el vino en Viver se aprecia la extraordinaria libertad que nos hemos autoimpuesto los autores en la elección de la mirada desde la que impulsamos el análisis del patrimonio, resultando evidentes los puentes entre la tradición y su actualización o sirviéndonos o enfocando sobre el arte contemporáneo ${ }^{2}$ y sus procesos pues, como se encuentra en plena sintonía con la época y el gusto que se está construyendo, se convierte en uno de los principales recursos para, en la línea de Fontal (2008), utilizar el patrimonio como un contenido, un objetivo, una finalidad o un medio, o como todo a la vez, en aquellas estructuras de educación patrimonial que estamos creando, teniendo muy en cuenta que "trabajar el patrimonio implica partir de los sujetos que aprenden, conformar sus identidades, hacer que se apropien simbólicamente de ese patrimonio" (Fontal, 2008, p. 104).

Calaf, al dar sentido a una genealogía pedagógica sobre la que fundamentar la didáctica del patrimonio, coincide con la posición favorable de Palacios (1996) al introducir estrategias educativas surgidas "desde propuestas de cambio social, resistencia y revolución" (Calaf, 2009, p. 72), caracterizadas por una línea muy activa de intervención -inducir, proponer, favorecer, crear y transformar- que, a nuestro modo de ver, no se queda en el aula, sino que proyecta al educando hacia las más sutiles y eficaces fórmulas de relación con el patrimonio, favorecedoras de su respeto, conservación, conocimiento y divulgación. Para ello, coincidimos también con la propuesta que hace la autora de la necesidad de recuperar, de modo consciente, las propuestas de Dewey, relacionadas con la educación experiencial la importancia de generar interés y de usar el juego como estrategia de conocimiento-, y las derivadas de Freire (1975) - presentar las situaciones de aprendizaje en torno al patrimonio cultural como problemas para resolver en el contexto de la vida real- y Gardner (1987) -inteligencias múltiples-, tal y como se percibe con claridad en la muestra de proyectos descritos en este estudio.

La aproximación de nuestro discurso a estas corrientes críticas está en la línea señalada por Barragán Rodríguez (2005, p. 56) de "cuestionar la educación exclusivamente reproductiva, cognitivista, orientada solo al conocimiento intelectual-racional” y no renunciar a la capacidad transformativa de la educación, aplicable además en diferentes contextos socioculturales. En los vectores de actuación de esas intervenciones nos encontramos con logros educativos que irían más allá del simple conocimiento del patrimonio y que se entienden como las líneas maestras de una práctica educativa que calificaríamos como de última generación: aprendizaje cooperativo, aprendizaje socioconstructivista, posiciones deliberativas, convivencia con la diversidad, transversalidad educativa respecto a valores éticos o aprendizaje estratégico basado en aprender a aprender (Barragán Rodríguez, 2005).

Vallés y Vayreda (2008, p. 69) señalan la conveniencia de que "las prácticas y las acciones educativas se formalicen en experiencias colectivas e innovadoras y donde la

Compartimos con Fontal (2004) que la dimensión contemporánea de la cultura no es diferente de la de otras épocas, cuyo patrimonio no se pone en duda y que cumple las mismas dimensiones fundamentales: presentación en soporte material, inmaterial y espiritual; atribución de valores; definición de identidades; caracterización de contextos y transmisión generacional. 
investigación, la experimentación, el diálogo y el intercambio de ideas permitan unas prácticas dinámicas e interactivas", conclusión a la que hemos accedido durante el desarrollo y la revisión de los resultados de los proyectos que se dan cita en este estudio.

Como se comprobará tras la lectura de los relatos sobre el Programa Pintia y la Fiesta del Vino de Viver, existe también en ellos una deriva desde los bienes patrimoniales a los individuos que se refuerza mediante la opinión compartida con Fontal, a través de Marín Cepeda (2013), acerca de que si concebimos la educación como disciplina preferente, la educación patrimonial se centrará en los sujetos, en sus aportaciones para el desarrollo integral de la persona y las relaciones que estos establecen con los bienes patrimoniales.

Por otro lado, el patrimonio permite indagar sobre los distintos tiempos de la cultura planteados por Fontal (2006) -la cultura del presente, la cultura del pasado, la cultura desde el presente, la cultura desde el pasado- lo que permite una gran diversidad de enfoques y acciones que incluyen utilizar la educación patrimonial para configurar una base cultural para el futuro, la configuración de identidades culturales o como elemento activo en la construcción del futuro, idea esta última que también impulsaron Vallés y Vayreda (2008, p. 69) al afirmar que el patrimonio debe ser entendido como "el nexo de unión del pasado y del presente y a su vez como motor y configurador del futuro".

En la aplicación de este razonamiento acerca de la virtud del patrimonio cultural como vía de conocimiento a través de las diferentes estrategias posibles desde la educación patrimonial, conviene hacer notar la posibilidad de invertir la dirección de los beneficios. Además de los percibidos desde la óptica de aquellos que experimentan el patrimonio como destinatarios finales del proceso, la educación patrimonial, cuando esquiva la mera imposición de fórmulas y significados mediante un diálogo rico, lleno de matices y capas de conocimiento que se desvelan experiencialmente, se convierte en un camino hermoso de transitar para el educador, pues le permite reconciliarse con la esencia primigenia de su labor.

Del mismo modo, se pueden reconocer en ambos proyectos las recomendaciones de Beck y Cable (1998) para la educación patrimonial del siglo XXI, las que sugiere Morales y otros (2001) para la interpretación del patrimonio, las del conocimiento informado recopiladas por Calaf (2009), o aquellas acerca de para qué, qué, cómo, a quién y dónde enseñar-aprender el patrimonio cultural propuestas por Fontal (2004), incluso cuando desarrollamos nuestra aproximación fuera del aula, en la propia comunidad, ante los bienes patrimoniales y en los museos.

Antes de dejar paso a los relatos de los proyectos señalaremos que, interpretando a Hammersley y Atkinson (1994), hemos elegido la etnografía como estrategia para contarlos porque nos permite extraer respuestas teóricas mediante la descripción narrativa de los hechos e introducir nuestros artefactos pedagógicos mediante la elaboración de esta fundamentación teórica desde la investigación cualitativa, pues las escrituras del yo "tienen en común su capacidad para filtrar, organizar y transformar la experiencia de lo personal, para reconstruir un discurso de conocimiento" (Agra Pardiñas, 2005, p. 137).

La importancia del uso de los géneros narrativos-descriptivos en la etnografía se debe, entre otros factores y de acuerdo con Velasco y Díaz de Rada (1997, p. 79), a la evolución del concepto de la antropología social "de ciencia de la conducta a arte de la interpretación de acciones significativas”. Esta evolución

requiere nuevos motivos narrativos, de manera que la etnografía ha de ser experimental, es decir, ha de abrir nuevos caminos, probar nuevas formas de discurso correspondientes 
a las circunstancias cambiantes de los pueblos y las culturas, de los grupos sociales y de las comunidades, y al continuo redescubrimiento que unos hacen de otros, reinventando imágenes de sí mismos y de los otros a medida que se ven afectados por nuevos cambios. (1997, p. 82).

\section{PRIMER VAIVÉN: LA NECESIDAD Y LA OPORTUNIDAD}

Cuando la voluntad y la oportunidad se encuentran y se dan la mano es inevitable no iniciar el camino; incluso, se genera una cierta necesidad de echar a andar, de explorar el territorio educativo, de afrontar peligros. Ese es el punto de partida común de la redacción de este artículo, pero lo es especialmente de la génesis de los proyectos de educación patrimonial Programa Pintia de Innovación Educativa y la Fiesta del Vino de Viver.

El docente precisa asumir retos cotidianos en educación, sentirse protagonista del proceso educativo y conseguir que el alumnado se sienta igual. Ahí está la raíz del Programa Pintia de Innovación Educativa: en una militancia activa por una educación diferente, posmoderna, intuitiva, participativa, identizadora y construida colectivamente entre los distintos agentes del proceso, en la que el patrimonio puede y debe jugar un papel axial.

El Programa Pintia (Colegio Safa-Grial, 2009-2010) nació de la idea de desarrollar un proyecto en torno a la arqueología como excusa para trabajar, desde la experiencia y la identidad, algunos de los contenidos curriculares de la asignatura de Historia de $2^{\circ}$ de Bachillerato y convertir el proceso en algo realmente significativo para los participantes.

La Edad de los Metales en la Península Ibérica es un contenido cualquiera y, como tal, no debería tener un desarrollo magnificado. Sin embargo, resulta una etapa especialmente atractiva de nuestro pasado y nos permite caminar por la transdisciplina y a abrir nuestra mente a otras maneras de acceder a los conocimientos.

Por su parte, en 2015, el Grupo de Recuperación de la Cultura del Vino de Viver (Castellón) planteó una propuesta al Colegio de Educación Infantil y Primaria Historiador Diago, para realizar una actividad de educación patrimonial sobre el patrimonio del vino. La Fiesta del Vino de Viver supone uno de los momentos culminantes de un proyecto realizado por voluntarios locales que se inicia en 2013 y centrado en la socialización de su patrimonio cultural a partir del establecimiento de vínculos afectivos.

El recorrido realizado por estos voluntarios, desde su creación hasta la Fiesta del Vino, refleja un proceso educativo complejo en el que se imbrican los ámbitos educativos tradicionales -formal, no formal e informal-. Su aproximación nos permitirá analizar un itinerario que quiere generar, mediante el diseño y desarrollo de espacios de encuentro y convivencia, procesos de identización y pertenencia de la comunidad con su patrimonio cultural.

\section{SEGUNDO VAIVÉN: LA COLABORACIÓN COMO SEÑAL DE IDENTIDAD}

Para el desarrollo del proyecto de recuperación de la cultura del vino que culminó en 2015, el Grupo de Viver contó con el acompañamiento técnico de Patrimoni - PEU. Patrimoni se enmarca en el Programa de Extensión Universitaria del Servicio de Actividades Socioculturales del Vicerrectorado de Cultura, Extensión Universitaria y Relaciones Institucionales de la Universitat Jaume I de Castellón. El PEU es un programa que posibilita 
un proceso colaborativo en red para el desarrollo del territorio. El modelo de presencia y participación territorial del PEU viene detallado en los estatutos de la UJI. Respecto al servicio a la sociedad, la universidad plantea "participar en el progreso y desarrollo de la sociedad, a través de la difusión, la valoración, la crítica y la transferencia de conocimiento al servicio de la cultura, de la calidad de vida y del desarrollo social y económico". Y en otro apartado de este mismo artículo 5, "promover actividades de difusión del conocimiento y de la cultura entre todos los sectores sociales y grupos de edad, a través de la extensión universitaria y de la formación permanente" (Artículo 5. Decreto 116/2010 del Consell. Estatutos de la Universitat Jaume I de Castellón).

Patrimoni es el proyecto de educación patrimonial del PEU. Surge en 2006 como consecuencia de la demanda de toda una serie de grupos locales con proyectos sobre conocimiento y puesta en valor del patrimonio para definir un espacio de aprendizaje compartido. El proyecto tiene un triple objeto: articular las necesidades formativas demandadas desde el territorio, llevar a cabo el asesoramiento necesario para el desarrollo de los proyectos locales y establecer una serie de puntos de encuentro desde los que poder conocerse, incorporar nuevas experiencias y reflexionar conjuntamente sobre el patrimonio cultural. El perfil de los miembros de Patrimoni - PEU es muy diverso, aunque podríamos caracterizarlo como voluntarios que quieren conocer y dar a conocer su patrimonio. Respecto al perfil, encontramos agricultores, albañiles, maestros, docentes jubilados o funcionarios que comparten el empeño por buscar espacios y acciones para aproximarse y socializar su patrimonio, para participar en procesos identitarios basados en la pertenencia y valor simbólico de su patrimonio y, junto a esta búsqueda, la preocupación por compartir lo que ellos sienten que significa el patrimonio con sus vecinos para, por un lado, garantizar la conservación de su patrimonio y, por otro lado, la continuidad de sus proyectos y acciones.

En Patrimoni - PEU, la formación se basa en un catálogo abierto de recursos formativos y didácticos al servicio de las necesidades de los grupos y tiene un carácter no finalista. Los cursos y talleres son impartidos por docentes y empresas especializadas. Por el carácter único de cada uno de los grupos de Patrimoni - PEU, la oferta formativa existente es revisada, actualizada y ampliada en función de las necesidades demandadas desde el territorio. Las iniciativas surgidas cuentan con un acompañamiento técnico centrado en la importancia del proceso, la metodología utilizada, la búsqueda horizontal de la participación y la definición de contenidos exportables. Una parte de este acompañamiento viene determinado, además, por el carácter del proyecto como laboratorio para la probatura de metodologías para el análisis a partir de las necesidades surgidas en el desarrollo de los proyectos.

En el proyecto de recuperación de la cultura del vino de Viver, el acompañamiento técnico de Patrimoni - PEU consistió en participar de manera horizontal en su desarrollo, aportar la experiencia del tutor en lo que se refiere a diseño, organización y proponer y planificar acciones para la socialización del proyecto. A lo largo del proyecto, las áreas temáticas abordadas fueron la recogida e investigación de los sistemas tradicionales de cultivo y cuidados de la viña, vendimia, elaboración del vino, comercialización (bodegas y fábricas de alcohol), consumo y productos derivados (gastronomía) y en la localización del patrimonio material e inmaterial relacionado (objetos relacionados con la vitivinicultura y un vocabulario en el que también se incluyen "digendas" que es como se conocen los refranes y las expresiones coloquiales).

En la gestación del Programa Pintia existía la necesidad y se presentó la oportunidad. Cuando un proyecto educativo huye de los convencionalismos, interpreta como 
oportunidades los problemas y apuesta por comprobar la profundidad de los charcos, es que va a ser algo diferente, innovador y relevante; pero en educación nada es posible únicamente desde la voluntad del docente si no cuenta con un alumnado receptivo, un respaldo institucional por parte del centro escolar y, en los casos más notables, el apoyo de una institución colaboradora externa.

El espaldarazo definitivo lo constituyó la colaboración del Centro de Estudios Vacceos Federico Wattenberg (CEVFW), cuyo director, Carlos Sanz Mínguez, puso sus recursos al servicio del Programa Pintia. El vínculo nació del convencimiento de que sería una oportunidad para ambas partes: el CEVFW alcanzaría repercusión en ámbitos que le eran ajenos y el proyecto lograría los apoyos técnicos que se necesitaban para poder desarrollarlo, pues además del acceso al material arqueológico original -que podría ser manipulado por los chicos-, aportaba tres miembros de su equipo científico -dos arqueólogas y un dibujante- que desarrollarían para nosotros unos talleres de aproximación al trabajo propio de un laboratorio de arqueología. Posteriormente se incorporó el Dr. Romero Carnicero, catedrático de Prehistoria y codirector del yacimiento.

Durante el proceso de implicación del alumnado surgió la posibilidad de presentar los resultados de nuestras investigaciones al concurso Los Nueve Secretos, convocado por la Fundación del Patrimonio Histórico de Castilla y León, que proporcionaba al proyecto un nuevo ámbito de visibilidad, nos estimulaba para trabajar más intensamente y acotaba la formación del equipo a ocho alumnos y dos profesores. El equipo se formó espontáneamente en la clase de Historia. Días antes habíamos prospectado un yacimiento vacceo y regresamos con algunos fragmentos de cerámica pintada a peine. Ya en el aula, desplegamos los restos sobre un par de mesas. Algunos alumnos se acercaron, los tomaron en sus manos, pasaron sus dedos por los bordes mientras prolongaban el rumbo como definiendo el perímetro o preguntaron el modo en que se habían pintado aquellos perfectos semicírculos concéntricos. Estos eran los buenos. Solo hubo que invitarlos. En otoño de 2012 decidimos lanzar una nueva edición (Programa Pintia 2.0); en la necrópolis aparecieron algunas tumbas de filiación femenina y el CEVFW quería realizar una investigación multidisciplinar, integrando a los alumnos del Colegio Safa-Grial en el equipo del CEVFW. Esta vez los invitados éramos nosotros. A la reunión informativa asistieron más de treinta alumnos y constituimos un equipo de veinte, incluidos dos participantes de la edición 1.0, ya en su etapa universitaria.

\section{TERCER VAIVÉN: RELATOS ENCADENADOS DE DOS PROYECTOS EN CONVERGENCIA}

\subsection{LOS PRIMEROS PASOS PARA LA SOCIALIZACIÓN DE LA CULTURA DEL VINO EN VIVER}

El proyecto de Viver surgió en 2013 cuando la concejala de cultura Isabel Mañes propuso, a un grupo de vecinos, la catalogación de los cubos de vino de la población con el acompañamiento técnico del proyecto Patrimoni - PEU. Los cubos, también llamados lagares, trules, botas o tinas en otros lugares, son construcciones monumentales que se utilizaban para recoger el mosto obtenido del pisado de la uva y almacenarlo mientras se transformaba en vino. En Viver y en la comarca del Alto Palancia se caracterizan por ser construcciones monumentales realizadas con piedras limpias de calar, rodeno o 
piedra tosca, cantos rodados, mortero y, para su interior, ladrillos de barro cocido que se repuntaban con cal grasa (en ocasiones mezclada con sangre de animales) para conseguir una mayor impermeabilización. Los cubos se construían en el interior de las casas y podían ser cilíndricos o cuadrangulares. Algunos de ellos, los más grandes, podían contener hasta treinta mil litros de vino, dato que nos hace reflexionar sobre la importancia del vino para el municipio. Por su experiencia y conocimiento del pueblo, el Grupo de Viver tenía constancia de la existencia de un buen número de cubos de vino repartidos entre el casco urbano y su término municipal. La investigación realizada, basada en entrevistas orales, ha permitido al grupo situar cerca de un centenar de cubos (Imagen 1).

Imagen 1. Acercando el patrimonio a los niños y niñas de Viver

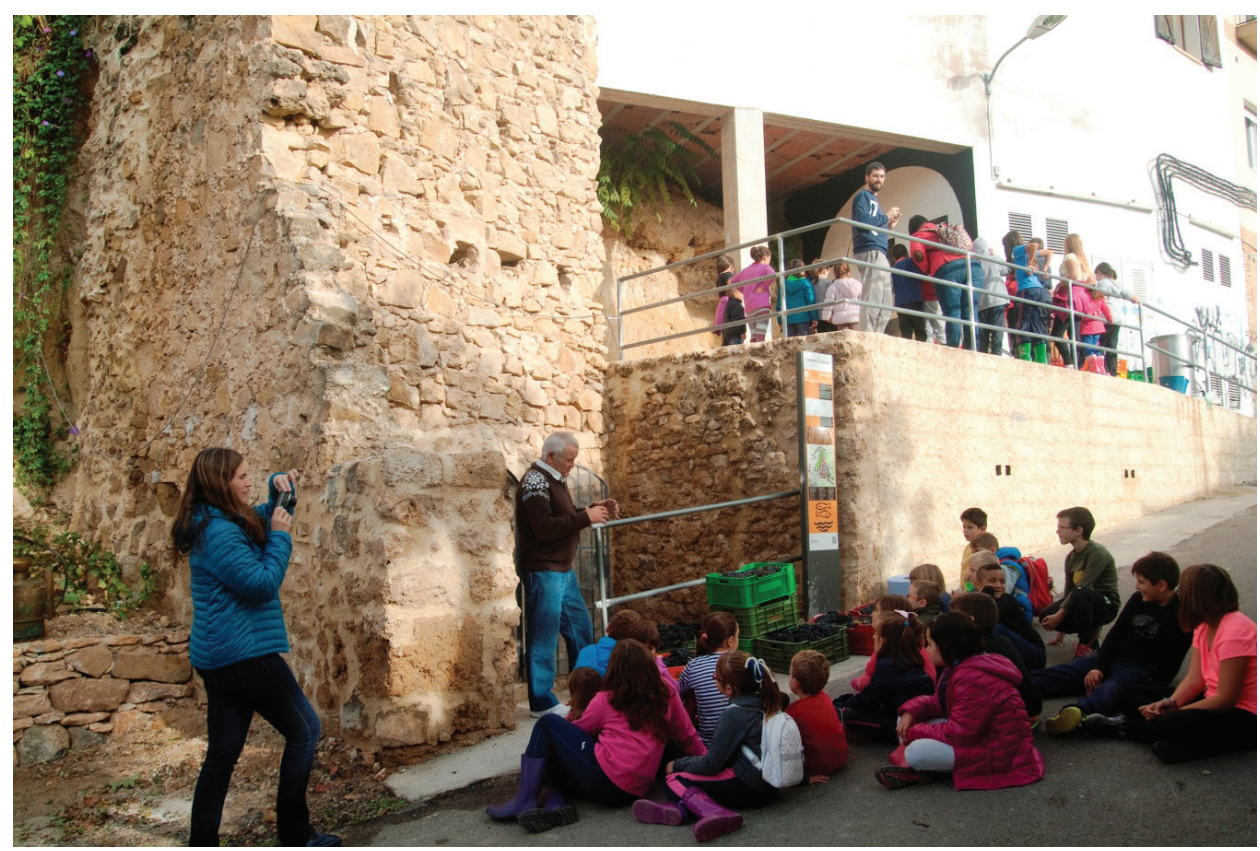

Fuente: Archivo fotográfico proyecto Patrimoni - PEU.

Como parte del acompañamiento de Patrimoni - PEU, el Grupo de Viver fue definiendo sus objetivos hasta plantear un proyecto para la recuperación y puesta en valor de la cultura material e inmaterial del vino en su población. En este proceso se realizó una definición consensuada por los miembros del grupo del concepto de patrimonio. En esta definición, destaca la importancia que el grupo da a conocer y socializar el patrimonio cultural a partir de procesos de identización y la importancia y necesidad de conectar con la población para compartir valores de pertenencia que enlacen patrimonio y personas (Sanjuán \& Mañes, 2013). Una parte muy importante para el Grupo de Viver ha sido la documentación de la presencia e importancia del vino en la población. En esta investigación, llevada a cabo por Ismael Sanjuán Monzonís, se ha realizado un recorrido que parte de la introducción del 
cultivo de la viña por los romanos hasta los inicios del siglo XX con la llegada de la plaga de la filoxera a Viver (1915), momento que supuso el abandono de su cultivo (Sanjuán \& Mañes, 2013).

\subsection{EL ÁREA ARQUEOLÓGICA PINTIA. TODO UN MUNDO POR DESCUBRIR}

Cum aliquid nescit... non evneritur. Cum aliquid non veneritur... nescit.

De entre todos los bienes culturales que atesoramos, seguramente, el patrimonio arqueológico es el más desconocido de todos ellos. Sin duda, tiene bastante que ver en esto el mero hecho de que la mayor parte del mismo se encuentre soterrado o ignoto.

[...] tuvimos bastante claro que el BIC objeto de estudio debía aportarnos algo más que el conocimiento en profundidad de algo ya presente en nuestra vida; tenía que apelar a nuestra condición de jóvenes curiosos sobre nuestro pasado, incluso del más remoto y desconocido. De ahí, quizá, nuestra determinación de estudiar un bien de nuestro patrimonio arqueológico, por la propia necesidad de desenterrar nuestras inquietudes si queremos conocerlas, como se hace con los ajuares vacceos.

[...] El patrimonio arqueológico forma parte de las señas de identidad de todos nosotros. El contacto directo con el mismo es un privilegio del que no todos los pueblos disponen. Es nuestro deber acercarnos a él con el convencimiento de que custodiamos un tesoro irrepetible.

Cuando algo no se conoce... no se respeta. Cuando algo no se respeta... se pierde . $^{3}$

El ramillete de objetivos que planteamos era bastante nutrido, destacaban algunos como profundizar en el conocimiento de nuestro patrimonio arqueológico mediante el estudio de un BIC; aprender a respetar el patrimonio histórico artístico y favorecer su conservación integrada; desarrollar la capacidad de trabajar en equipo; tomar contacto con la investigación científica elaborando un proyecto multidisciplinar, sumando participantes procedentes de distintos itinerarios educativos; favorecer un aprendizaje eficaz e interesado a partir de la significatividad de los conocimientos adquiridos; hacer uso de las TIC, tanto en el proceso de investigación como en la elaboración de las conclusiones; aprender y poner en práctica las técnicas de investigación histórica y arqueológica; fomentar la integración de los participantes y profesores coordinadores en un grupo de trabajo; utilizar las redes sociales como herramienta de comunicación, intercambio y promoción del proyecto; desarrollar habilidades artísticas y entenderlas como una herramienta fundamental para el desarrollo de proyectos de toda índole; establecer vínculos entre pasado y presente a través de la realización de actividades formativas en el campo de las Artes Plásticas y las Ciencias Sociales o recuperar labores y oficios tradicionales, hoy en desuso, a través de la actualización de sus fines.

Los tiempos del proyecto se distribuyeron entre noviembre de 2009 y abril de 2010 , articulándose en cuatro fases que agruparían las actividades de aproximación, investigación

Resulta interesante señalar la coincidencia de la elección de esta cita como argumento casi fundacional del Programa Pintia, en 2010, con el texto del Plan Nacional de Educación Patrimonial (PNEP), donde se dice que "Sólo se protege y conserva lo que se conoce y se valora" (Carrión, 2015, p. 4). 
MOVIMIENTO PENDULAR: PROYECTOS DE EDUCACIÓN PATRIMONIAL ENTRE LA ESFERA FORMAL Y LA INFORMAL. EL PROGRAMA PINTIA DE INNOVACIÓN EDUCATIVA Y LA FIESTA DEL VINO DE VIVER

y difusión previstas. La investigación tuvo siempre una doble dirección, que se desarrolló sincrónicamente: por un lado, se elaboró el texto que analizaba el estado del BIC a través de su pasado, situación actual y viabilidad de futuro y, por otro, se realizó toda una serie de actividades paralelas, que obtuvieron visibilidad a través de una gran cantidad de materiales complementarios, con los que nos hicimos una aproximación al yacimiento desde una óptica caleidoscópica y periférica.

El futuro de Pintia está en excavarlo e iluminar aquello que contiene, algo que no podíamos hacer. Por ello nuestro estudio no podía ser convencional, necesitaba enriquecerse con nuestra experiencia personal; así que hicimos que el patrimonio enterrado se encarnara en nosotros realizando la investigación en primera persona y haciendo fluir el pasado vacceo en los productos finales que fuimos elaborando, que situamos en el mismo plano de diálogo que los materiales arqueológicos de los que partían. Así, nos acercamos a la arqueología desde la antropología y los procesos de patrimonialización.

Las actividades formativas del Programa Pintia comenzaron desentrañando las tareas propias de un equipo de arqueólogos - prospección, excavación, reconstrucción, restauración, restitución, difusión-, pero también establecieron miradas distantes, desde la frontera, que acercaron a los estudiantes al mundo vacceo favoreciendo una expresión de sí mismos que entroncase con el pasado vacceo y con su propia condición de jóvenes. La mayor parte del Programa Pintia se levantó a partir de experiencias de este tipo, desde el convencimiento de que construir los conocimientos sobre el pasado por medio de una investigación histórica al uso era tan solo uno de los rumbos posibles y que, en este sentido, caminar por la periferia de las cosas se puede convertir en una estrategia muy certera para llegar a las mismas conclusiones (Imagen 2).

Imagen 2. Trabajo de los alumnos del Colegio Safa-Grial en el Laboratorio de Arqueología de la Universidad de Valladolid, con los materiales originales del yacimiento de Pintia

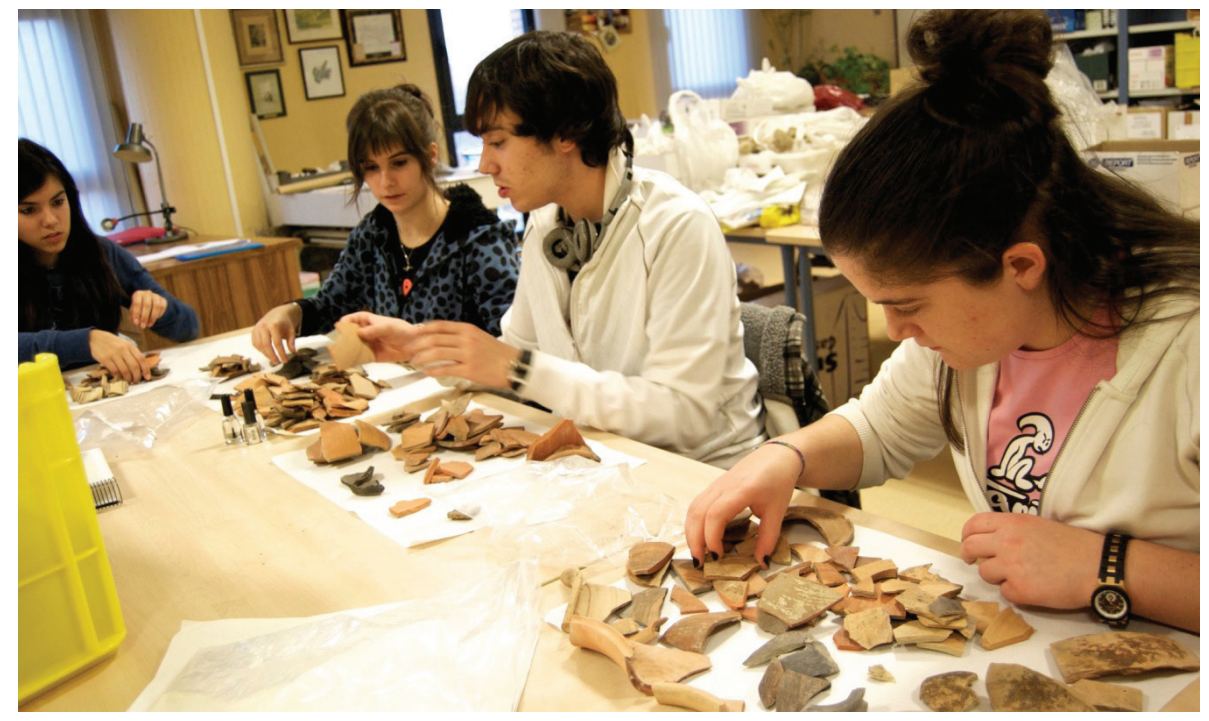

Fuente: Programa Pintia de Innovación Educativa, Pablo de Castro. 
MOVIMIENTO PENDULAR: PROYECTOS DE EDUCACIÓN PATRIMONIAL ENTRE LA ESFERA FORMAL Y LA INFORMAL. EL PROGRAMA PINTIA DE INNOVACIÓN EDUCATIVA Y LA FIESTA DEL VINO DE VIVER

\section{CUARTO VAIVÉN: LA CRISTALIZACIÓN DE LOS PROYECTOS DE EDUCACIÓN PATRIMONIAL A TRAVÉS DE LOS PROCESOS DE IDENTIZACIÓN}

\subsection{LA FIESTA DEL VINO DE VIVER}

En verano de 2014, el grupo había recogido una parte importante del patrimonio material e inmaterial del vino en Viver y surgió una pregunta: ¿Y ahora qué? Para intentar dar respuesta a esta cuestión, desde Patrimoni - PEU se ideó y propuso la realización de un taller reflexivo para el análisis transversal del presente y futuro del proyecto y Grupo de Viver (Imagen 3). Con el Taller Colaborativo Interdisciplinar - TCI de Viver

se pretende analizar de manera participativa y horizontal el proyecto de recuperación del patrimonio cultural tradicional del vino que se está llevando a cabo desde 2013. El objetivo ha sido iniciar un proceso de participación que se prolongue en el tiempo y del que surjan planteamientos, recomendaciones e iniciativas a medio y largo plazo en lo que se refiere a la socialización, interpretación, musealización, comunicación, difusión, etcétera, del proyecto que han iniciado. (Portolés \& Torres, 2015, p.13).

Imagen 3. Taller Colaborativo Interdisciplinar de Viver - TCI Viver

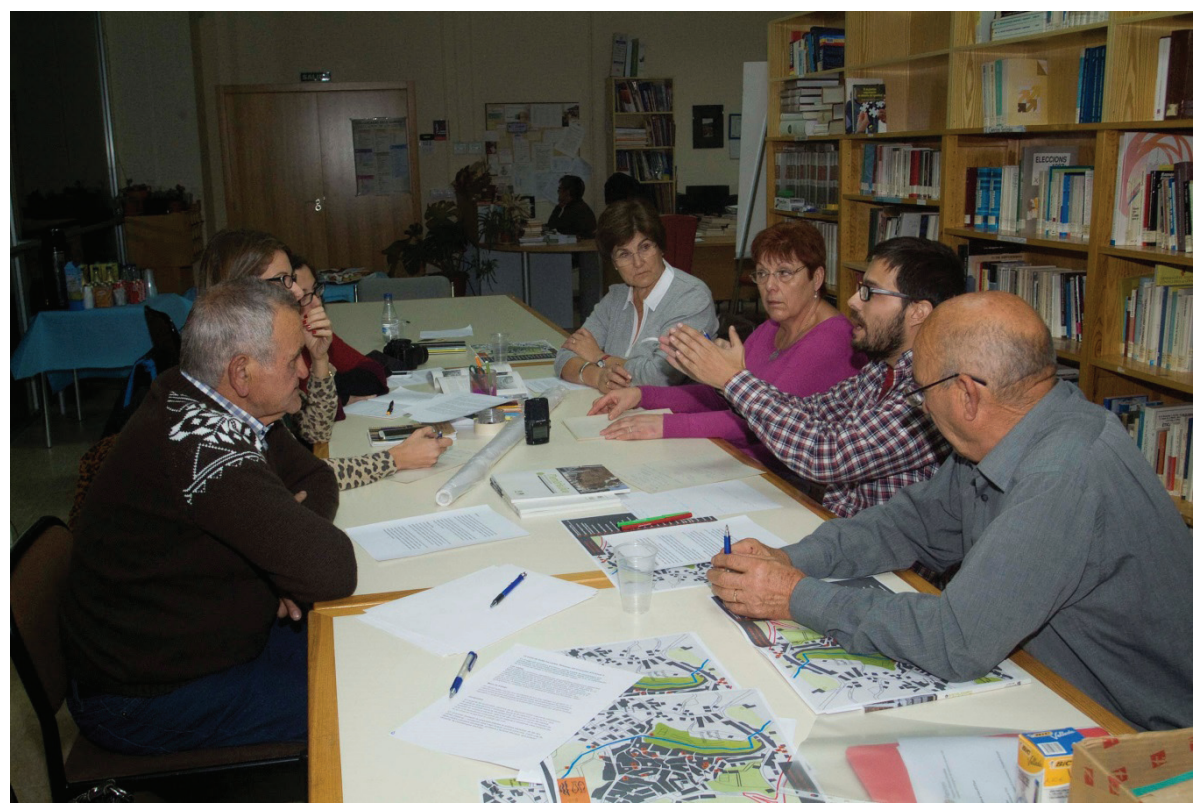

Fuente: Archivo fotográfico proyecto Patrimoni - PEU.

El TCI conjugó en su desarrollo varios espacios de encuentro para el análisis y reflexión del proyecto. La primera fase del taller fue la de presentación y preparación y se desarrolló en dos planos: presencial y virtual. La parte presencial estuvo formada por toda una serie 
de reuniones de coordinación y planificación con el grupo local y con representantes del tejido asociativo de la población. En el plano virtual se realizó una serie de encuentros en Twitter. El objetivo de estos encuentros fue el de presentar el proyecto y marco del Grupo de Viver a la comunidad virtual. En este pre taller se consensuaron las dinámicas de la fase presencial del taller. Esta definición colaborativa del TCI forma parte de la esencia participativa y horizontal que definen a Patrimoni - PEU. Para cada uno de los encuentros en Twitter, se realizó un resumen con las aportaciones y un storify con los tweets que utilizaron el hashtag \#TCIViver.

Respecto a los participantes, el TCI se caracterizó por la búsqueda de una participación de carácter transversal en la que coincidieron tanto actores internos (miembros del grupo, tejido asociativo, interesados locales) como externos (miembros de otros grupos locales del proyecto Patrimoni - PEU, actores externos invitados explícitamente a participar en el taller por su perfil técnico y experiencia y colaboraciones puntuales mediante interacciones en Twitter).

Con todos estos elementos se diseñó, de manera colaborativa, un taller formado por dos jornadas presenciales en Viver de carácter inmersivo en el que se desarrollaron mesas de trabajo, visitas al patrimonio del vino y un concierto de música experimental desde uno de los cubos de vino. En todas estas actividades compartieron análisis los distintos actores arriba enunciados.

Una de las recomendaciones surgidas en el TCI y asumidas por el Grupo de Viver fue la implicación con la escuela de Viver para, juntos, desarrollar acciones que vincularan el conocimiento recogido por el grupo a lo largo de su proyecto. En mayo de 2015, el Grupo de Recuperación de la Cultura del Vino de Viver se reunió con los maestros y maestras del colegio para presentar su trabajo y proponer el diseño conjunto de una acción que pudiera desarrollarse en el ámbito escolar en la que el vino fuera el recurso central para la aproximación de los niños y niñas de Viver hacia su patrimonio cultural. Todo el trabajo realizado cristalizó los días 22 y 23 de octubre de 2015 con la celebración de la Fiesta del Vino de Viver.

El 22 de octubre fue el día dedicado a la vendimia. Los niños y niñas de infantil y primaria salieron a primera hora hacia el viñedo andando los casi tres kilómetros que separan ambos lugares. Una vez llegaron, fueron recibidos por el Grupo de Viver que les hizo una pequeña explicación de su trabajo y de la importancia del vino para la población. Ya en el viñedo, aprendieron a cortar los racimos y a dejarlos cuidadosamente en las cajas. En apenas 45 minutos, los 120 niños y niñas del Colegio Historiador Diago habían recogido más de 400 kilos de uva y conocido, de la mano de los miembros del Grupo de Viver, un trabajo que seguramente realizaron muchos de sus antepasados.

El día siguiente, la Fiesta del Vino se trasladó a las proximidades del cubo de la "rocha Palmera". Este cubo es de propiedad municipal y ha sido limpiado y consolidado, con la ayuda del Ayuntamiento de Viver y las recomendaciones técnicas realizadas por Patrimoni - PEU, por los miembros del grupo. El acto central de esta segunda jornada de educación patrimonial fue el pisado de la uva en el cubo. El contenido simbólico de esta acción es muy potente. Hacía cien años que ese cubo no recibía uva ni contenía mosto. Un siglo después de la plaga de la filoxera, el cubo de la "rocha Palmera" recuperaba, por unas horas, su lugar en el pueblo y la función para la que fue creado, dejando atrás sus años de abandono.

Desde la escuela, los docentes diseñaron toda una serie de actividades que se sumaron a las planificadas por el Grupo de Viver. En los diferentes rincones temáticos preparados, 
los niños y niñas transitaron atesorando conocimientos, valores y recuerdos sobre el vino y su importancia. El Grupo de Recuperación de la Cultura del Vino de Viver preparó las siguientes propuestas: exposición interpretativa de objetos del vino, charla sobre el modo en el que se construían los cubos de vino, pisado de uva, demostración de la elaboración mecánica de mosto y degustación. Por su parte, los maestros y maestras prepararon juegos, canciones, un mural de pintura sobre la temática del vino y un taller de modelado de herramientas con plastilina. La Fiesta del Vino es la materialización de la voluntad y necesidad del Grupo de Viver de compartir su proyecto y el patrimonio local con su población. Desde la escuela como correa de transmisión desde la que buscar el reencuentro de los vecinos y vecinas con su patrimonio ${ }^{4}$.

\subsection{LOS PROCESOS Y PRODUCTOS DEL PROGRAMA PINTIA}

El planteamiento de las actividades en torno al mundo vacceo debía seducir a los estudiantes, pero también apelar a su propia identidad si queríamos salvar con éxito el abismo entre los trabajos escolares convencionales y la intimidad de nuestras propuestas; por eso los profesores-coordinadores nos implicamos como uno más en el proceso de trabajo, realizando en vanguardia cada tarea propuesta, y las actividades se introdujeron con gran expectación y una denominación en latín, que añadía un halo de prestigio y misterio a lo que hacíamos.

Un protocolo detallado describía la actividad, los materiales necesarios, los objetivos y las posibles acciones a realizar. Este es el resumen de aquellas que compusieron el Programa Pintia.

Tempus praeteritum praesentem facit supuso un acercamiento a la cultura vaccea desde la indagación de su presencia en la toponimia, los nombres de las instituciones, las calles, los negocios que hoy día nos remiten a Pintia y/o la cultura vaccea.

Inter humum caelumque consistió en actualizar la práctica funeraria vaccea de colocar un ajuar junto a la urna cineraria, mediante la reconstrucción/simulación de los propios ajuares de cada uno de nosotros. Este depósito se fotografió y fue objeto de parangón con el ajuar vacceo que había sido asignado a cada participante. El proceso se completó con la acción performativa de actualizar el rito, practicando un depósito colectivo en el campo y construyendo un documental (Imagen 4).

Descriptio rei fue el modo en que asumimos el papel del arqueólogo, acometiendo la limpieza, consolidación y restauración del material arqueológico original del yacimiento, junto a su análisis científico. Cumplimentamos unas fichas de catálogo en las que, junto a datos científicos, dibujos propios, fotografías incluimos nuestras aproximaciones literarias a esas piezas que, en primera persona, evidenciaban la identificación con el difunto o el objeto, y dieron lugar a las colecciones de cuentos Los últimos momentos y La memoria de las cosas. En la edición 2.0 del programa los datos obtenidos se incorporaron a la memoria de investigación del CEVFW sobre la excavación del yacimiento.

La Fiesta del Vino fue documentada por el Programa de Extensión Universitaria. Como resultado de este trabajo se publicó digitalmente un álbum con una selección de fotografías de estas dos jornadas en el sitio web "flickr" (https://www.flickr. com/photos/87737534@N04/sets/72157658148525574/) y un video en el canal de Youtube del PEU UJI (https://youtu. be/5XUKCUHiRtY). Podemos encontrar las reflexiones y valoraciones del Grupo de Viver sobre estas dos jornadas de socialización del patrimonio en El patrimonio de Viver en la escuela: La Fiesta del Vino (Sanjuán, Mañes \& Portolés, 2016). 


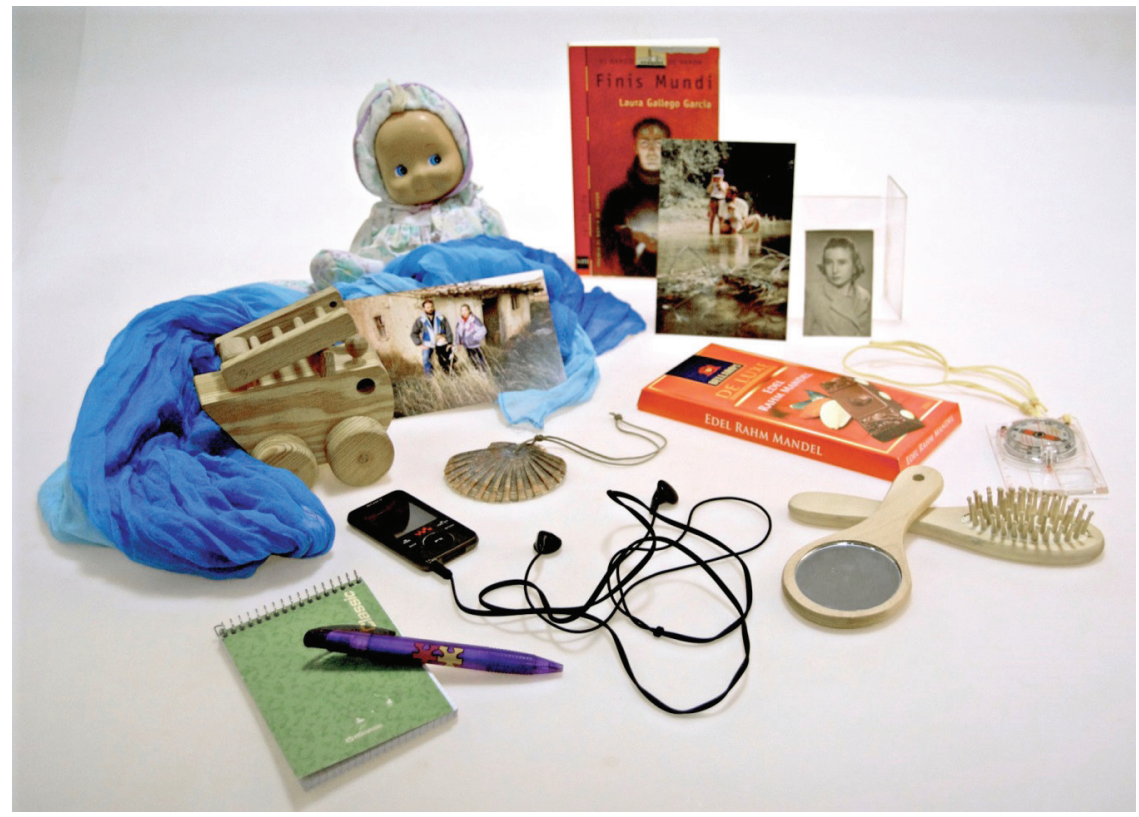

Fuente: Programa Pintia de Innovación Educativa, Pablo de Castro.

Memoria terrae nos permitió entender el repertorio cerámico vacceo desde la producción que hicimos de esas cerámicas en el taller del ceramista Carlos Jimeno. Además de replicar diversos tipos de vasos - con decoración incisa, excisa, a peine- nos atrevimos a actualizar sus modelos de cara a un uso contemporáneo.

Itinera descripta propuso itinerarios interpretativos para recorrer el yacimiento de Pintia. Para ello se creó un tríptico informativo que recogía las rutas y aportaba la información oportuna para una comprensión no erudita.

Opus Pintia se convirtió en nuestra personal apuesta por la visibilización del Área Arqueológica Pintia a través del diseño y la producción de diversos mensajes publicitarios que vertimos en soportes tan diversos como carteles, vallas publicitarias, diseños para el exterior de un autobús o cuñas publicitarias para la radio y televisión/internet.

De re aedificatoria aportó planos de las diferentes zonas del yacimiento, que permitían una adecuada interpretación del trazado urbano.

Imaginum collectio es el corpus de documentación fotográfica del proyecto, que se hizo visible mediante un libro de fotos y varias colecciones monográficas de imágenes montadas como película -Dentro de la cata, Laboratorio de Arqueología UVa, Memoria terrae y Resumen de actividades-.

Palabras de luz es una intervención de land art realizada, con las últimas luces del día, para establecer un nexo entre el pasado y el presente de Padilla Duero, tomando el propio pueblo y el yacimiento de Pintia como escenario. 
El cortometraje de ficción lo utilizamos en las dos ediciones del Programa Pintia para indagar, aprender y dar visibilidad al yacimiento. En la versión 1.0 los participantes escribieron, rodaron y editaron el cortometraje La Caja, un thriller de ficción arqueológica. En la edición 2.0 el equipo rodó Obituario. Tres historias de vida y muerte en el mundo vacceo, un cortometraje de animación con muñecos playmobil que relataba las tres prácticas funerarias vacceas documentadas en Pintia.

También recurrimos al documental para describir los entresijos y actividades del proyecto; así nacieron Área Arqueológica Pintia. Todo un mundo por descubrir -que resumía nuestra singular aproximación al mundo vacceo desde la propia piel- y Cápsula del tiempo -que narraba la acción performática de la deposición de nuestro ajuar colectivo-.

Finamente, creamos una web/blog/wiki que funcionó como entorno de comunicación entre los miembros del proyecto, lugar de intercambio de documentación, foro de exposición de los materiales elaborados y canal de difusión del BIC y del propio proyecto.

El proyecto resultó un éxito, alcanzando una valoración de 8,81 puntos sobre 10 en las encuestas de evaluación cumplimentadas por los alumnos. También son buenos los resultados generales relativos al cumplimiento de los objetivos ( 3,4 sobre 4 puntos $)$-de los coordinadores $(3,5)$ y de los participantes $(3,62)$ - y el grado de satisfacción $(3,3$ sobre 4 puntos) sobre varios aspectos como el trabajo en equipo $(3,5)$, la interacción alumnos/ profesores $(3,5)$, las actividades realizadas $(3,75)$ y su planificación en el tiempo $(2,25)$, los materiales finales $(3,87)$ o la implicación en el proyecto de los alumnos $(3,37)$ y los coordinadores $(3,5)$.

Pero la valoración que consideramos más relevante es que los estudiantes otorgaron la máxima puntuación a la hora de evaluar el grado en que su participación en el programa les dejaría huella; además, es extraordinariamente fácil de corroborar mediante una evaluación cualitativa del programa o la lectura del capítulo escrito por tres de los participantes ${ }^{5}$ en Visiones caleidoscópicas (Fontal, García Ceballos \& Ibáñez, 2015), que aporta una narración del proyecto desde la óptica del alumno.

Los reconocimientos externos también dan validez al proyecto y, de entre ellos, destaca que el Programa Pintia de Innovación Educativa 1.0 se alzó con el primer premio del Concurso Los Nueve Secretos "por la original presentación y la nueva mirada sobre el "Área arqueológica Pintia. Todo un mundo por descubrir". También recibió una Mención de Honor en los Premios Vaccea 2010

[...] por el interés, sensibilidad y entusiasmo demostrados en su acercamiento al mundo de la Arqueología y por considerar su actuación un modelo de innovación educativa que propicia la identificación ciudadana con su patrimonio arqueológico más oculto y, en consecuencia, el aprecio por la conservación del mismo. ${ }^{6}$

Cabrerizo, García Rubio y Peral participaron en la primera edición del Programa Pintia de Innovación Educativa y recibieron la propuesta de escribir este artículo por parte de los propios coordinadores del libro. Por entonces, ya hacía algunos meses que habían dejado el Colegio Safa-Grial e iniciado su formación universitaria, que ninguno de ellos orientó hacia el Patrimonio, el Arte o la Arqueología; a mi modo de ver la lectura del artículo transmite con claridad el modo en que la participación en el proyecto ha definido su intensa relación con estas disciplinas.

6 Véase el artículo Premios Vaccea 2010 en la revista Vaccea Anuario (2010, pp. 42-47) en el Anexo A2 Visibilidad y transferencia de los proyectos (A2.1 Prensa escrita. 05 Programa Pintia). 
Estudios Pedagógicos XLIII, $N^{\circ}$ 4: 7-28, 2017

MOVIMIENTO PENDULAR: PROYECTOS DE EDUCACIÓN PATRIMONIAL ENTRE LA ESFERA FORMAL Y LA INFORMAL. EL PROGRAMA PINTIA DE INNOVACIÓN EDUCATIVA Y LA FIESTA DEL VINO DE VIVER

Este reconocimiento resulta más valioso si tenemos en cuenta las escasas ocasiones en que la Universidad vuelve su mirada hacia las enseñanzas medias.

Además, las películas rodadas - La caja y Obituario- fueron seleccionadas para concurrir a más de una docena de festivales, obteniendo diversos premios y visibilizando, desde su proyección pública, el propio yacimiento y la cultura vaccea en los ámbitos nacional e internacional (Imagen 5).

Imagen 5. Cartel de la película Obituario. Tres historias de vida y muerte en el mundo vacceo, rodado por los participantes en el Programa Pintia de Innovación Educativa 2.0

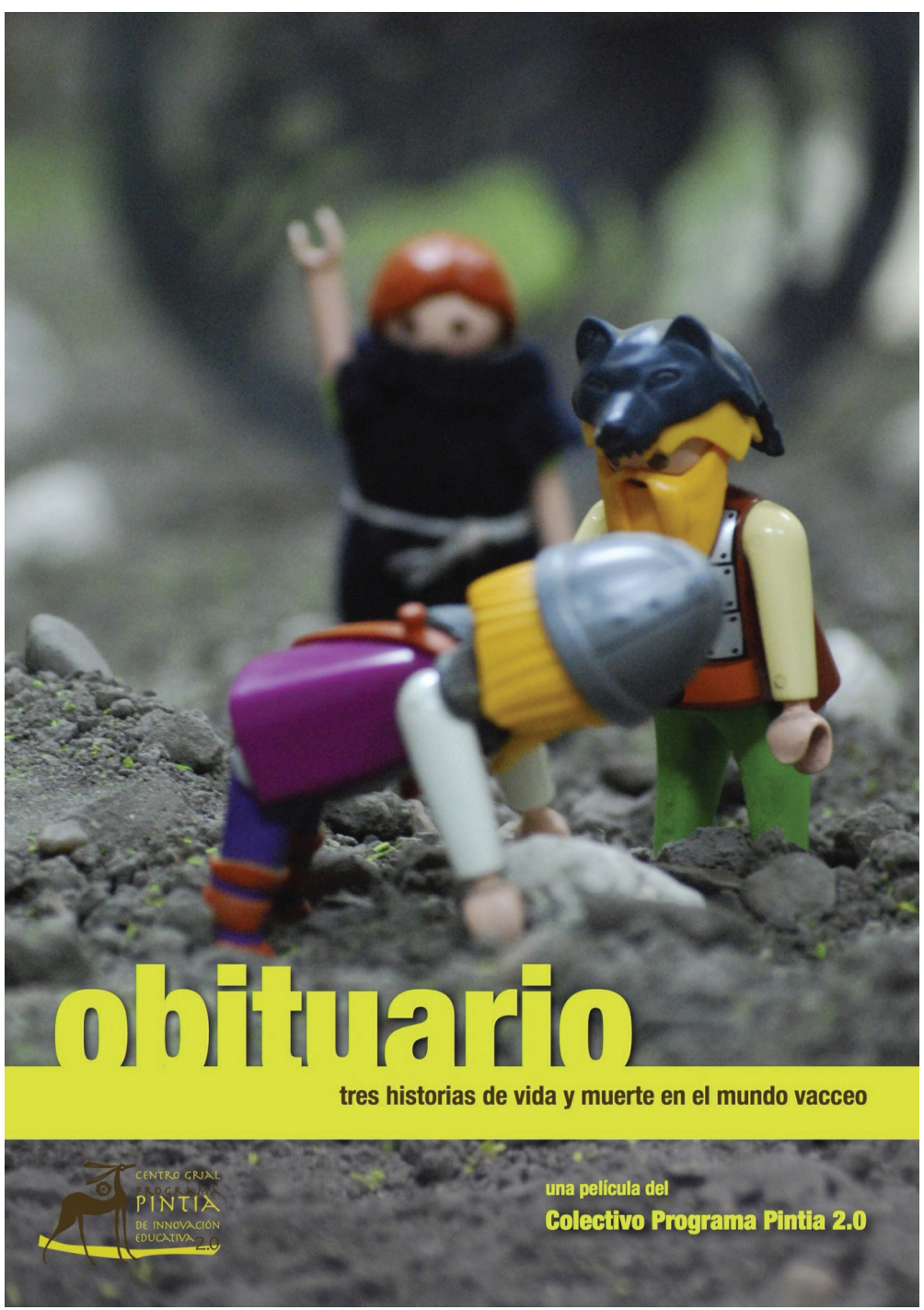

Fuente: Programa Pintia de Innovación Educativa, Pablo de Castro. 


\section{PROYECCIÓN Y CONTINUIDAD. DESMONTANDO LA DIALÉCTICA ENTRE LA ESFERA FORMAL Y LA INFORMAL EN LOS PROCESOS EDUCATIVOS}

Muy lejos ya de la concepción hermética y desconectada de los tres ámbitos educativos tradicionalmente propuestos y tipificados como formal, no formal e informal, los proyectos sobre conocimiento y puesta en valor del patrimonio plantean, cada vez más, espacios permeables en los que se complementan, en un mismo proyecto y desde su concepción, acciones que conjugan estos contextos. Precisamente, la educación patrimonial requiere y alcanza su máxima expresión en programaciones que conectan los tres ámbitos evitando "diseños aislados, desconectados e independientes" (Carrión, 2015, p. 5). Esta capilaridad proporciona a los proyectos y actividades un contexto más amplio que contribuye a enriquecer los procesos educativos mediante la introducción de diferentes actores y situaciones. Además, la incorporación de los distintos ámbitos a un proyecto educativo no tiene un patrón determinado y es por ello que encontramos tanto experiencias que parten de contextos formales como otras que surgen de ámbitos no formales o informales. Del mismo modo, la evolución de estos procesos tampoco sigue un orden establecido dando lugar a un amplio abanico de posibilidades en las que se conjugan, en función de su desarrollo, diferentes contextos, actores y situaciones.

Como resultado de esta mezcolanza, la educación patrimonial se presenta como un proceso abierto, amplio, rico, complejo y transversal que busca la vinculación múltiple del sujeto hacia su patrimonio y que nos acerca a la metáfora del caleidoscopio referido por Fontal, García e Ibáñez en "Educación y Patrimonio: visiones caleidoscópicas" y que nos aporta una visión que es capaz de mostrar "los diferentes agentes que entrelazan y reflejan sus narraciones del proyecto presentado, proyectando una visión compleja, pero cohesionada y relacionada" (Fontal et al., 2015, p. 18). Por lo tanto, las relaciones existentes entre educación y patrimonio son múltiples. Dependen de la aproximación y relación establecida entre sujeto y objeto y de la finalidad y lugar que ocupe el patrimonio en el proceso educativo. Y para ello, la educación patrimonial ofrece un enfoque "de carácter globalizador, integrador y simbiótico" que "coloca el acento en la dimensión relacional existente, no solo entre ambos términos, sino entre los elementos que integran o constituyen cada uno de ellos" (Carrión, 2015, p.13).

Los ejemplos presentados del Programa Pintia y de la Fiesta del Vino de Viver nos permiten categorizar un modelo híbrido de aprendizaje formal no formal de carácter acumulativo y basado en la educación patrimonial.

El Programa Pintia de Innovación Educativa parte del aprendizaje formal, pero va derivando hacia el no formal a medida que avanza. Está claro que la colaboración entre dos instituciones educativas como el Colegio Safa-Grial y la Universidad de Valladolid -a través del CEVFW y el Departamento de Arqueología- posiciona el proyecto en ese ámbito, como lo hace el hecho de que determine el objeto de trabajo desde el currículo de la asignatura de Historia de $2^{\circ}$ de Bachillerato o que se canalice hacia alumnos de enseñanzas medias como destinatarios del mismo; pero si algo caracteriza este proyecto es su amplitud de miras, concebida desde un acercamiento periférico y transdisciplinar (Moraes, 2010; Morin, 1996) a los contenidos que, además de exigir la colaboración de agentes externos, alejados de la órbita de la enseñanza reglada, nos ha obligado a invertir la tradicional dirección de difusión de los contenidos (profesor alumno) empleando otra en la que es la experiencia personal, desde la vivencia íntima del contacto con el material arqueológico o 
Estudios Pedagógicos XLIII, N 4: 7-28, 2017

MOVIMIENTO PENDULAR: PROYECTOS DE EDUCACIÓN PATRIMONIAL ENTRE LA ESFERA FORMAL Y LA INFORMAL. EL PROGRAMA PINTIA DE INNOVACIÓN EDUCATIVA Y LA FIESTA DEL VINO DE VIVER

la participación en procesos de identización y patrimonialización, la auténtica generatriz de los aprendizajes. La formación práctica recibida en el CEVFW (arqueología, dibujo arqueológico, cerámica) y aquellos conceptos incorporados al proyecto $-\mathrm{O}$ al bagaje personal de los participantes- como fruto de conversaciones informales o entrevistas semiestructuradas con los habitantes de Padilla de Duero o el personal científico, se combinan para dibujar líneas de horizontalidad y transversalidad que terminan por definir un modelo permeable, en el que la propia reflexión introspectiva de los alumnos en torno al patrimonio actúa como catalizador de todo el proceso educativo.

En la Fiesta del Vino de Viver, reconocemos diferentes modelos de aprendizaje que se superponen atendiendo a los distintos actores participantes. Para los miembros del Grupo de Viver, el proceso educativo continuo realizado en Viver se enmarca inicialmente en el ámbito no formal. De acuerdo con el Plan Nacional de Educación y Patrimonio de 2015, "forman parte de este ámbito todas las acciones educativas estructuradas y reguladas no por normas de naturaleza jurídica sino por el ejercicio de las competencias culturales de diferentes tipos de instituciones" (Carrión, 2015, p. 5). En este ámbito, la formación se destina a cubrir las demandas del Grupo para llevar a cabo su proyecto y plantea una alteración del modelo tradicional de aprendizaje, de arriba abajo, para definir un modelo más horizontal y solidario donde el proceso educativo se entiende como un proceso en el que todos participan y aportan sus conocimientos y experiencia. En este sentido, la experiencia se entiende como un elemento fundamental en la definición del aprendizaje, puesto que la demanda del grupo se refiere, sobre todo, a una necesidad de acceder a este tipo de conocimientos. Aun así, este aprendizaje vivencial se conjuga con otra formación de carácter técnico y específico en la que el docente aporta las herramientas necesarias (catalogación) para que el Grupo pueda realizar su proyecto. La introducción de dinámicas basadas en la colaboración y la horizontalidad, como la que hemos visto con el caso del Taller Colaborativo Interdisciplinar, proporcionan al grupo, además, una aproximación a toda una serie de conocimientos y contenidos transversales (Imagen 6).

Imagen 6. La Fiesta del Vino de Viver constituye un ejemplo de fusión de los ámbitos educativos formal, no formal e informal

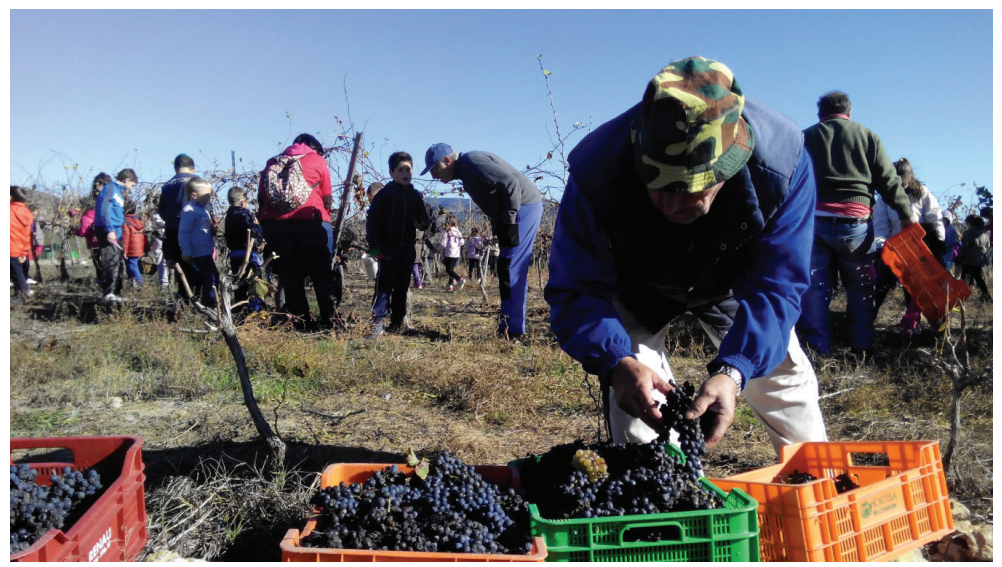

Fuente: Archivo fotográfico del proyecto Patrimoni - PEU. 
Por su parte, para los niños y niñas, el recorrido parte de una primera aproximación de carácter formal realizada por los docentes del colegio Historiador Diago de Viver y realizada anteriormente a la Fiesta del Vino. En este itinerario se suman los miembros del Grupo de Viver hasta configurar un modelo en el que se compaginan los enfoques formal e informal. Ofreciendo al proceso de aprendizaje de los escolares un marco más amplio en el que, conceptos como identificación, vinculación y patrimonio, se conjugan con el resultado de una experiencia educativa transversal, amplia y rica.

Algunos de los elementos clave que hemos detectado en los dos proyectos analizados son la importancia de la identización y pertenencia como parte esencial en el desarrollo del proyecto, la importancia de un diseño colaborativo y horizontal y la creatividad.

En el proyecto de Viver destaca la búsqueda de la horizontalidad como punto de partida desde el que establecer relaciones entre los distintos actores que convergen en el grupo. Para que esta horizontalidad sea efectiva, la colaboración es esencial y cada uno de los miembros realiza sus aportaciones desde su experiencia, trayectoria y disponibilidad. Como hemos podido ver, para el Grupo de Viver es vital que la comunidad se aproxime al valor / valores de su patrimonio y lo entienda y reconozca como propio, como herencia compartida con condiciones, como recurso para el desarrollo de su población y como argumento central para construir una comunidad vinculada, concienciada y activa con su patrimonio, capaz de desarrollar acciones y proyectos que generen relaciones en torno al patrimonio. Al mismo tiempo, desde el Grupo se considera también imprescindible el conocimiento y reconocimiento, por parte de los vecinos y vecinas de la población, del grupo y del proyecto en curso. Precisamente, una de las consecuencias resultantes de la identización y pertenencia de los miembros del grupo de Viver hacia su patrimonio es la responsabilidad y la necesidad de garantizar su continuidad. Para explicar este fenómeno, puede servirnos la preocupación análoga de aquel que mira con cierta intranquilidad lo que será de todo aquello que ama cuando ya no esté para cuidarlo. Porque, la identización genera emoción y vínculo. Establece conexiones muy fuertes que despiertan la responsabilidad y también una preocupación reflexionada y responsable hacia el futuro de su patrimonio y, por extensión, de su comunidad.

Patrimoni - PEU es un proyecto en el que la innovación social en el campo del patrimonio es fundamental. El investigador Jesús Fernández nos propone tres factores que deben darse juntos para hablar de innovación social referida al patrimonio: se crean nuevas soluciones para el cumplimiento de los objetivos de conservación, gestión, difusión, defensa o puesta en valor del patrimonio cultural, se cubren necesidades sociales y se crean nuevos tipos de relaciones (Fernández, 2016). En Patrimoni - PEU, la innovación social en el campo del patrimonio cultural se caracteriza por la creación de nuevas formas de organización, prácticas, productos, servicios, nuevas normas, leyes e innovaciones abiertas y en abierto. ${ }^{7}$ Todos estos elementos aparecen reflejados en el proyecto del Grupo de Recuperación de la Cultura del Vino de Viver y en la Fiesta del Vino analizada en este artículo y también la hallamos en el diseño y realización del Taller Colaborativo Interdisciplinar - TCI anteriormente descrito. Esta innovación se encuentra, como hemos visto, al servicio del desarrollo del proyecto y se centra en el codiseño de acciones que le permitan evolucionar, adaptarse, contraerse o ampliarse. Esta innovación social en el

Todos estos aspectos aparecen recogidos en la ficha del proyecto Patrimoni - PEU del proyecto Hesiod, Observatorio de Innovación Social y Patrimonio de Jesús Fernández Fernández, que puede consultarse en http://hesiod.eu/ 
campo del patrimonio cultural no está exenta de una creatividad directamente conectada con la caracterización de Patrimoni - PEU como laboratorio para el diseño y desarrollo de acciones basadas en la colaboración, la participación y la horizontalidad.

En Pintia, la identización (Gómez Redondo, 2013) y la patrimonialización (Fontal, 2004) son el principio dinámico y propia razón de ser del programa, que fue diseñado con el anhelo de que los participantes trabajaran en contacto con materiales arqueológicos originales y reprodujeran los diversos procesos asociados a ellos -producción cerámica, catalogación de bienes culturales, excavación arqueológica, ritualización de un ajuardesde la consciencia de que un yacimiento por excavar ofrece pocas oportunidades para su conocimiento profundo más allá de la revisión de la bibliografía publicada en torno a él o la contemplación distante de unos pocos materiales expuestos en la vitrina de un museo; pero también desde la certeza de que solo pegándonos al barro, al terruño, a las lágrimas de la pérdida, al sabor de la sangre de una herida abierta a hierro podríamos rescatar la memoria vaccea y tatuarla sobre nuestra piel, para que, visible, pueda acariciarse.

En esa relación multidireccional que se entabla entre bien patrimonial profesor alumno también se establecen procesos de identización a través del sentido de pertenencia a un grupo, el de los agentes del proyecto, que conecta con el patrimonio desde la esfera del significado que ellos mismos le otorgan a cada sesión de trabajo; el carisma de que sea algo secreto y exclusivo fortalece esos lazos pues, en palabras de Torregrosa y Falcón (2013, p. 116) "lo secreto cuando fluye deja paso a la concreción de reuniones intensas, aquellas en las cuales circula un conocimiento sensible, un fuego mutuo que se contagia, que une".

Por otro lado, la verticalidad de un proyecto diseñado desde el lado del docente y que se implanta en el alumnado desde el convencimiento de que resulta adecuado para la consecución de unos determinados objetivos educativos, deja de ser tal desde el momento en que entran en liza la complicidad del trabajo en un grupo, donde profesores y alumnos comparten funciones y opinan con tal libertad que hacen dinámica la estructura inicial y favorecen una mayor horizontalidad y participación de la prevista. La estructura del Programa Pintia demuestra su capacidad para no permanecer inmóvil y se ha ido enriqueciendo con aportaciones posteriores, que la han hecho más oportuna dentro de su contexto cultural y educativo.

Pintia es un proyecto pleno de creatividad y de artisticidad, en el que se supera el debate excluyente que disocia los proyectos educativos de los proyectos artísticos, ya desde la propia génesis de los mismos, pues se alinea claramente con un enfoque procedente de la A/R/Tography dada su clara intención de

integrar en sus obras la teoría, la praxis y la poiesis, o la teoría-investigación, la enseñanza-aprendizaje y la creación-artística. Comenzamos con esos tres roles y esas tres formas de pensamiento, no tanto como entidades separadas, sino como identidades conectadas e integradas que están siempre presentes en nuestro trabajo. (Marín Viadel, 2011, p. 32).

Pero también asume la investigación educativa basada en las artes (ABER) -que usa los procesos artísticos actuales como estrategias de investigación e indaga sobre las cuestiones educativas ofreciendo resultados con evidente calidad estética y artística- y las de la investigación visual basada en las artes (ABVR) -“donde los datos no se encuentran, sino que son construidos" (Marín Viadel, 2011, p. 32). En estas líneas de actuación se 
encuentra la filosofía de los numerosos productos finales realizados como parte del proceso de trabajo del Programa Pintia.

Puede concluirse atrevidamente de la lectura de estos ejemplos que los proyectos sobre Pintia y Viver no son solamente paradigmas que muestran un camino acertado en educación patrimonial, son el propio camino, el único posible: el vaivén del péndulo que solo puede ir de aquí a allí, y de vuelta a aquí, entre las personas y el patrimonio.

\section{REFERENCIAS BIBLIOGRÁFICAS}

Agra Pardiñas, M.J. (2005). El vuelo de la mariposa: la investigación artístico-narrativa como herramienta de formación. En R. Marín Viadel (Ed.), Investigación en Educación Artística: Temas, métodos y técnicas de indagación sobre el aprendizaje y la enseñanza de las artes y culturas visuales (pp. 127-150). Granada: Universidad de Granada y Universidad de Sevilla.

Barragán Rodríguez, J.M. (2005). Investigación en educación artística: temas, métodos y técnicas de indagación sobre el aprendizaje y la enseñanza de las artes y culturas visuales. En R. Marín Viadel (Coord.), Investigación en educación artística: temas, métodos y técnicas de indagación sobre el aprendizaje y la enseñanza de las artes y culturas visuales (pp. 43-80). Granada: Universidad de Granada.

Beck, L., \& Cable, T. (1998). Interpretation for the 21th Century-Fifteen Guiding Principles for Interpreting Nature and Culture. Champagne, Eire: Sagamore Publishing.

Cabrerizo, M., García Rubio, C., \& Peral, D. (2015). Programa Pintia de Innovación Educativa. Arqueología introspectiva: descubridores de nuevos tesoros. En O. Fontal, S. García Ceballos \& Á. Ibáñez (Coords.), Educación y patrimonio: visiones caleidoscópicas (pp. 53-60). Gijón: Trea.

Calaf, R. (2009). Didáctica del patrimonio. Epistemología, metodología y estudio de casos. Gijón: Trea.

Calaf, R., \& Fontal, O. (2010). Cómo enseñar arte en la escuela. Madrid: Síntesis.

Carrión, A. (Coord.). (2015). Plan Nacional de Educación y Patrimonio. Ministerio de Educación Cultura y Deporte. Recuperado de http://www.mecd.gob.es/planes-nacionales/dam/ jcr:1ece6634-3e47-4484-a469-198e17d46c9b/folleto-imprimir-plan-educacion.pdf

Eco, U. (1984). Obra abierta. Barcelona: Ariel.

Estatutos de la Universitat Jaume I de Castellón. Artículo 5. Decreto 116/2010 del Consell. Recuperado el 25 de marzo de 2017 desde http://www.dogv.gva.es/datos/2010/08/31/pdf/2010_9480.pdf

Fernández, J. (2016). Proyecto HESIOD. Definiendo e identificando ecosistemas de innovación social-patrimonial. PH. Boletín del Instituto Andaluz del Patrimonio Histórico, 90, 236-239.

Fontal, O. (2004). La dimensión contemporánea de la cultura. Nuevos planteamientos para el patrimonio cultural y su educación. En R. Calaf \& O. Fontal (Coords.), Comunicación educativa del patrimonio: referentes, modelos y ejemplos (pp. 81-104). Gijón: Trea.

Fontal, O. (2006). Claves del patrimonio cultural del presente y desde el presente para abordar su enseñanza. Pulso, 29, 9-31.

Fontal, O. (2008). La importancia de la dimensión humana en la didáctica del patrimonio. En S. Mateos (Coord.), La comunicación global del patrimonio cultural (pp. 79-110). Gijón: Trea.

Fontal, O., García Ceballos, S., \& Ibáñez, A. (Coords.). (2015). Educación y patrimonio: visiones caleidoscópicas. Gijón: Trea.

Freire, P. (1975). La educación como práctica de la libertad. México: Siglo XXI editores.

Gardner, H. (1987). La teoría de las inteligencias múltiples. México: Fondo de Cultura.

Gómez Redondo, M.C. (2013). Procesos de patrimonialización en el arte contemporáneo: diseño de un artefacto educativo para la identización (Tesis doctoral inédita). Universidad de Valladolid.

Hammersley, M., \& Atkinson, P. (1994). Etnografía. Métodos de investigación. Barcelona: Paidós. 
Estudios Pedagógicos XLIII, N 4: 7-28, 2017

MOVIMIENTO PENDULAR: PROYECTOS DE EDUCACIÓN PATRIMONIAL ENTRE LA ESFERA FORMAL Y LA

INFORMAL. EL PROGRAMA PINTIA DE INNOVACIÓN EDUCATIVA Y LA FIESTA DEL VINO DE VIVER

Juanola, R., \& Calbó, M. (2004). Hacia modelos globales en educación artística. En R. Calaf \& O. Fontal (Coords.), Comunicación educativa del patrimonio: referentes, modelos y ejemplos (pp. 105-136). Gijón: Trea.

Marín Cepeda, S. (2013). Patrimonios (in)accesibles: la educación del patrimonio orientada a la normalización. En O. Fontal (Coord.), La educación patrimonial. Del patrimonio a las personas (pp. 93-106). Gijón: Trea.

Marín Viadel, R. (2011). Las Metodologías Artísticas de Investigación y la Investigación Educativa Basada en las Artes Visuales (sobre el paisaje de la Depresión Cuadrada de Bruce Nauman). En J. Roldán \& R. Marín Viadel (Coords.), Metodologías artísticas de investigación en educación (pp. 14-39). Málaga: Ediciones Aljibe.

Moraes, M.C. (2010). Transdisciplinariedad y educación. Rizoma Freiriano, 6, 1-19. Recuperado de http://www.rizoma-freireano.org/index.php/transdisciplinariedad-y-educacion--maria-candidamoraes

Morales, J., Bayod, MC., López, R., Prats, J., \& Buesa, D. (2001). Aspectos didácticos de las ciencias sociales. Zaragoza: ICE de la Universidad de Zaragoza.

Morin, E. (1996). La transdisciplinariedad. Manifiesto. Sonora: Multiversidad Mundo Real Edgar Morin, A.C.

Palacios, J. (1996). La cuestión escolar. Críticas y alternativas. Barcelona: Laia.

Portolés, A., \& Torres, C. (2015). Buscando una nueva metodología para Patrimoni: la Asamblea de Grupos y el Taller Colaborativo Interdisciplinar \#TCI. En Memòria Viva. Publicación del proyecto Patrimoni del Programa de Extensión Universitaria 7 (pp. 13-21). España: Universitat Jaume I.

Sanjuán, I., Mañes, I., \& Portolés, A. (2016). El patrimonio de Viver en la escuela: La Fiesta del Vino. En Memòria Viva. Publicación del proyecto Patrimoni del Programa de Extensión Universitaria 8 (pp. 50-56). España: Universitat Jaume I.

Sanjuán, I., \& Mañes, I. (2013). El patrimoni de la vitivinicultura de Viver. En Memòria Viva. Publicación del proyecto Patrimoni del Programa de Extensión Universitaria 8 (pp. 42-53). España: Universitat Jaume I.

Torregrosa, A., \& Falcón, M. (2013). Patrimonios instintivos. En R. Huerta \& de la R. Calle (Eds.), Patrimonios migrantes (pp. 125-132). Valencia: Editorial Publicacions de la Universitat de València.

UNESCO. (2003). Convención para la Salvaguardia del Patrimonio Cultural Inmaterial. París. Recuperado de http://unesdoc.unesco.org/images/0013/001325/132540s.pdf

Vallés, J., \& Vayreda, M. (2008). Experiencias en la educación del patrimonio. Construyendo puentes para un futuro inclusivo. En Patrimonio y sociedad. Aprendiendo con arte (pp. 69-84). Pamplona: Cederna-Garalur.

Velasco, H., \& Díaz de Rada, A. (1997). La lógica de la investigación etnográfica. Un modelo de trabajo para etnógrafos de la escuela. Madrid: Trotta. 